\title{
Impact of Exposure to Verbal Abuse on Nursing Students' Emotional Labor and Clinical Practice Stress During Clinical Training
}

\author{
Hae Young Woo \\ Lecturer, College of Nursing, Hanyang University, 222 Wangsimniro, Seongdong- \\ gu, Seoul 133-791, Korea \\ E-mail: why996527@hanyang.ac.kr
}

\begin{abstract}
This study aimed to investigate the level of verbal abuse and emotional labor and clinical practice stress of nursing students during clinical practice and determine the effects of the exposure to verbal abuse on emotional labor and clinical practice stress. 212 nursing students, who were juniors and seniors performing clinical practice in Seoul, participated in this study and the data were collected from October to November 2013. The collected data were analyzed using descriptive statistics, Pearson's correlation coefficients, and stepwise multiple regression analysis. Significant positive correlation was found among verbal abuse, emotional labor, and clinical practice stress; verbal abuse accounted for $10.4 \%$ of emotional labor and $33.8 \%$ of clinical practice stress. These results demonstrate that nursing students are exposed to verbal abuse during clinical practice and may consequently suffer from greater practice stress and emotional labor. The results are expected to be used as fundamental data that can help improve the quality of practical education and the practice environment and develop nursing education programs.
\end{abstract}

Keywords: verbal abuse, emotional labor, clinical practice stress, nursing student

\section{Introduction}

Nursing education involves both theoretical and practical education to give a comprehensive understanding of human beings and the internal and external environments surrounding them and to solve various problems that may occur in interactions. In other words, nursing education is the process in which nursing students acquire all the theoretical knowledge necessary to perform their duties as a nurse, explore methods to apply their knowledge to an actual nursing situation, and acquire practical techniques through clinical practice [1]. In particular, clinical practice is an essential course in which they are not only allowed to get practical knowledge and experiences required of nurses in nursing education in addition to theoretical education but also get values, attitudes, and professional images required of nurses and acquire duties [2, 3]. Through the clinical practice, nursing students may experience various nursing situations and make preparations so that they can perform duties to meet the social concerns and requirements for health.

However, nursing students may experience clinical practice stress due to the unfamiliar environment of clinical sites, fear and anxiety about mistakes during the practice, excessive tasks, role conflicts and limited knowledge, limitations in the clinical application of theories they have learned at school, unpredictable crisis situations, interpersonal relationships with the patients and their caregivers, and so on [4]. Most students indicate the need for practical education; however, they are rarely satisfied with clinical practice, get increasingly more stressed from the uninstructive practical environment, limited knowledge, and repetition of simple nursing practice, and get fear, 
fatigued, and angry instead [3]. If such clinical practice stress is not relieved, nursing students may get afraid of practice, lose confidence in nursing, and even become skeptical about their major in nursing; consequently, they may become daunted and frustrated badly [5]. Moreover, it can negatively affect nursing professional values and even threaten physical health $[6,7]$.

The term emotional labor was used to describe how individuals suppress or subordinate their feelings in order to create an atmosphere in which others feel they are safe and cared for $[8,9]$. Emotional labor is an essential and important part of the culture of caring [10] and has become important in nursing discussion [11]. Research has explored the concept of emotional labor [12] and how it is utilized in nursing practice [10, 13] and nursing education [14]. Emotional labor is commonly used by nurses caring for patients [15]. Members of the nursing profession have been identified as being vulnerable to experiencing verbal abuse, and this can results in a variety of negative consequences for healthcare organization and staff.

In a healthcare site for practice, nursing students, who are pre-service healthcare providers, may experience emotional labor similar to that of the medical staff. Since nursing is a process of meeting the health-related needs of patients through interaction with them [16], nurses need to make objective observation and rational judgment of the patients' conditions or nursing situations in therapeutic relationships with the aim of achieving the patients' health-related goal. To do this, nurses try to stand neutral emotionally instead of being caught up in the situation [17]. In doing so, they may control feelings or emotions that occur in their mind, regulate emotions that inhibit work performance, and express emotions helpful to the patient's health, instead of their own emotions. In this way, they come to experience emotional labor, which is an effort to express emotions that meet socially expected roles and professional codes instead of their own emotions. Morris and Feldman [18] defined emotional labor as an effort and controlled plan to express proper emotions expected by society or to achieve a goal through interpersonal interaction and described it in terms of frequency, intensity, and emotional dissonance.

Grandey [19] noted that emotional labor could be acquired through observation or through a series of training courses since it is an artificial act of controlling one's own emotions and expressing proper emotions with the objective of performing a specific duty. A nursing student who tries to acquire practical acts next to a nurse may also observe the nurse's emotional control and acquire expression rules for patients. To get better evaluation during practice, nursing students come to control their emotions and engage in emotional labor to meet the needs of a situation. In other words, emotional labor may be experienced not only by nurses but also by nursing students who try to adapt to expectations in their job [8]. Consequently, it can produce negative effects: they can experience burn out, see their self-esteem lowered, or give up their studies. In addition, emotional labor is expected to increase practice stress.

It has been reported that healthcare providers are highly vulnerable to physical and verbal abuse from patients and their caregivers; in particular, most nurses have been exposed to verbal abuse [20]. While a diversity of studies have recently been conducted on the nurses' exposure to verbal abuse, nursing students who perform clinical practice in a similar environment to nurses and who are beneficiaries of learning based on the practice, critics, and non-professionals, may suffer various types of abuse from the medical staff, including nurses, patients, and the patients' caregivers. Still, very few studies have been conducted on this matter among nursing students participating in clinical practice.

It is therefore necessary to investigate the actual state of verbal abuse nursing students, who are expected to become nurses, suffer and to allow them to cope well with any verbal abuse. This study aims to determine its effects on emotional labor and practice stress, help 
nursing students establish nursing values as a good nursing professional, and improve the quality of nursing by creating a safe environment for practice.

\section{Method}

\subsection{Design}

This is a descriptive research conducted to investigate verbal abuse, emotional labor, and clinical practice stress among nursing students who have performed clinical practice.

\subsection{Sample}

Convenience sampling was made with nursing students who were at universities in Seoul and had performed nursing practice for at least fifteen weeks in a semester. The number of subjects was determined using a G*Power 3.1.2 program. 212 out of 250 questionnaires were returned and were finally analyzed [21].

\subsection{Instrument}

\subsubsection{Verbal Abuse}

Seven items concerning verbal abuse were selected from the abuse scale developed by Yoon [22] and employed by Shin [23] to measure verbal abuse with a total of 35 items by offender type (patient, caregiver, doctor, registered nurse, and other staff members). A five-point Likert scale-from 1 (not abused) for the past year to 5 (very frequently abused) — was used to measure verbal abuse. Verbal abuse was scored out of 5 on average, with a higher score meaning a greater degree of verbal abuse a nurse experienced. Offenders were classified into patients, caregivers, doctors, registered nurses, and other staff members to score verbal abuse, with a higher score meaning a greater degree of verbal abuse from the offender.

\subsubsection{Emotional Labor}

The instrument developed by Kim [24] on the basis of Morris and Feldman [18] was used to measure emotional labor. This instrument consisted of a total of 9 items about the sub-factors of emotional labor: 3 about frequency of emotional expression, 3 about attention in emotional expression, and 3 about emotional dissonance. A five-point Likert scale - from 1 (absolutely no) to 5 (absolutely yes) — was used. A higher score meant a higher level of emotional labor. For reliability of the instrument in this study, Cronbach's alpha was .806 .

\subsubsection{Clinical Practice Stress}

The instrument developed by Beck and Srivastsva [25] and adapted by Kim and Lee [4] was used to measure clinical practice stress. It consisted of 24 items: 5 for the practical education environment, 6 for undesirable role models, 4 for the burden of practical tasks, 4 for conflicts in interpersonal relationships, and 5 for conflicts with patients. Each item had a five-point Likert scale, with a higher score meaning a higher level of clinical practice stress. For the reliability of the instrument in this study, Cronbach's alpha was .860.

\subsection{Data Collection and Ethical Consideration}

This study was conducted among nursing students, who were juniors and seniors having performed clinical practice in Seoul. The data were collected with the approval of the Institutional Review Board in Hanyang University from October to November 2013. 
Participation in the study was entirely voluntary and all the participants provided informed consent. With the ethical aspect taken into account, the participants were given explanation of the specific purpose and methods of the study; afterwards, those agreeing to participate in the research were given explanation of anonymity, confidentiality, and right to veto participation in the research. A survey was then conducted among the subjects consenting to participate in the research.

\subsection{Data Analysis}

The collected data were analyzed using an SPSS Win 19.0 program. The general characteristics of the subjects were measured in frequency and percentage while the reliability of variables was expressed in the value of Cronbach's alpha. The exposure to verbal abuse, emotional labor, and clinical practice stress was measured in the mean and standard deviation. The correlation between variables was analyzed using Pearson's correlation coefficient. Stepwise multiple regression analysis was used to determine the effects of the exposure to verbal abuse on emotional labor and clinical practice stress.

\section{Results}

\subsection{General Characteristics of Subjects}

$91 \%$ of the subjects were female and $9 \%$ were male; they were 22.2 years old on average. $36.8 \%$ were juniors and $54.2 \%$ were seniors. $34 \%$ performed clinical practice in a semester (15 weeks) and $58 \%$ in three semesters. 95\% did not receive education about how to cope with verbal abuse $\langle$ Table $1>$.

\subsection{Verbal Abuse Experience}

While the subjects were rarely exposed to verbal abuse during clinical practice, they scored highest on average for the level of verbal abuse from patients. The most frequent type of verbal abuse from nurses was speaking impolitely, followed by verbally disregarding; likewise, they scored highest for speaking impolitely in case of patients and their family<Table 2>.

\subsection{Emotional Labor Level}

The subjects scored an average of $3.28 \pm 0.56$ out of 5 for the level of emotional labor. As for its sub-areas, they scored $3.75 \pm 0.5$ for frequency of emotional expression, $3.27 \pm 0.62$ for attention in emotional expression, and $2.82 \pm 0.73$ for emotional dissonance $\langle$ Table 3$\rangle$.

\subsection{Clinical Practice Stress Level}

They scored an average of $3.12 \pm 0.46$ out of 5 for the level of clinical practice stress; as for its sub-areas, they scored highest with $3.92 \pm 0.59$ for the practical education environment and lowest with $2.48 \pm 0.62$ for conflicts with patients <Table $3>$. 
Table 1. General Characteristics

$(N=212)$

\begin{tabular}{cccc}
\hline Characteristics & Categories & $\mathrm{N}(\%)$ & Mean \pm SD \\
\hline Gender & Male & $19(9.0)$ & \\
Age & Female & $193(91.0)$ & $22.2 \pm 2.4$ \\
& & & \\
Grade & Third & $78(36.8)$ & \\
& Fourth & $134(54.2)$ & \\
Religion & & & \\
& Yes & $97(45.8)$ & \\
& No & $115(55.9)$ & \\
Experience period of & & \\
clinical training & 2 semesters & $72(34.0)$ & \\
& 4 semesters & $123(2.8)$ & \\
& 5 semesters & $5(2.4)$ & \\
& or more & $6(2.5)$ & \\
Education about & & & \\
how to cope with & No & $202(95.3)$ \\
verbal abuse & 2 session & $7(3.3)$ & \\
\hline
\end{tabular}

Table 2. Verbal Abuse Experience

\begin{tabular}{|c|c|c|c|c|c|}
\hline \multirow{2}{*}{ Contents } & $\mathrm{RN}$ & Doctor & $\begin{array}{l}\text { Other } \\
\text { staffs }\end{array}$ & Patients & $\begin{array}{c}\text { Family of } \\
\text { patients }\end{array}$ \\
\hline & Mean $\pm S D$ & Mean $\pm S D$ & Mean $\pm S D$ & Mean \pm SD & Mean $\pm S D$ \\
\hline 1. Swearing & $1.69 \pm 1.85$ & $1.91 \pm 1.05$ & $1.57 \pm 0.78$ & $2.36 \pm 1.00$ & $2.17 \pm 1.00$ \\
\hline 2. Yelling & $2.08 \pm 0.94$ & $2.04 \pm 1.05$ & $1.52 \pm 0.71$ & $2.54 \pm 1.10$ & $2.47 \pm .1 .17$ \\
\hline 3. Speaking impolitely & $3.03 \pm 1.19$ & $2.52 \pm 1.26$ & $2.00 \pm 1.02$ & $3.18 \pm 1.09$ & $3.05 \pm 1.13$ \\
\hline 4. Blackmailing & $1.22 \pm 0.50$ & $1.22 \pm 0.55$ & $1.17 \pm 0.42$ & $1.32 \pm .69$ & $1.34 \pm 0.74$ \\
\hline 5. Disregarding verbally & $2.34 \pm 1.08$ & $2.14 \pm 1.24$ & $1.57 \pm 0.86$ & $2.19 \pm 1.15$ & $2.13 \pm 1.10$ \\
\hline $\begin{array}{l}\text { 6. Finishing talk } \\
\text { one-sidedly }\end{array}$ & $2.71 \pm 1.25$ & $2.17 \pm 1.28$ & $1.57 \pm 0.83$ & $1.81 \pm 0.87$ & $1.78 \pm 0.86$ \\
\hline $\begin{array}{l}\text { 7. Inquiring severely } \\
\text { in group }\end{array}$ & $1.41 \pm 0.77$ & $1.40 \pm 0.88$ & $1.27 \pm 0.58$ & $1.49 \pm 0.88$ & $1.56 \pm 0.96$ \\
\hline Total & $2.07 \pm 0.62$ & $1.91 \pm 0.76$ & $1.52 \pm 0.56$ & $2.13 \pm 0.66$ & $2.07 \pm 0.68$ \\
\hline
\end{tabular}


Table 3. Level of Emotional Labor and Clinical Practice Stress ( $N=212)$

\begin{tabular}{|c|c|c|}
\hline Variable & Sub-category & Mean $\pm S D$ \\
\hline \multirow[t]{4}{*}{ Emotional labor } & $\begin{array}{c}\text { Frequency of emotional } \\
\text { expression }\end{array}$ & $3.75 \pm .65$. \\
\hline & $\begin{array}{c}\text { Attention in emotional } \\
\text { expression }\end{array}$ & $3.27 \pm 0.62$ \\
\hline & Emotional dissonance & $2.82 \pm 0.73$ \\
\hline & Total & $3.28 \pm 0.56$ \\
\hline \multirow[t]{6}{*}{ Clinical practice stress } & $\begin{array}{l}\text { Practical education } \\
\text { environment }\end{array}$ & $3.92 \pm 0.59$ \\
\hline & Undesirable role model & $3.21 \pm 0.65$ \\
\hline & Burden of practical tasks & $3.37 \pm 0.65$ \\
\hline & $\begin{array}{l}\text { Conflicts in interpersonal } \\
\text { relationships }\end{array}$ & $2.50 \pm 0.63$ \\
\hline & Conflicts with patients & $2.48 \pm 0.62$ \\
\hline & Total & $3.12 \pm 0.46$ \\
\hline
\end{tabular}

\subsection{Correlation among Verbal Abuse, Emotional Labor and Clinical Practice Stress}

Emotional labor had significantly positive correlation with the exposure to verbal abuse and clinical practice stress. Statistically significant positive correlation was found between the exposure to verbal abuse and clinical practice stress $\langle$ Table 4$\rangle$.

Table 4. Correlation among Verbal Abuse, Clinical Practice Stress and Clinical Practice Stress $(N=212)$

\begin{tabular}{ccc}
\hline Variable & Emotional labor & Verbal abuse \\
\cline { 2 - 3 } Verbal abuse & $\mathrm{r}(\mathrm{p})$ & $\mathrm{r}(\mathrm{p})$ \\
\hline Clinical practice stress & $.278(<.000)$ & \\
\hline
\end{tabular}

\subsection{Effects of Verbal Abuse on Emotional Labor and Clinical Practice Stress}

Verbal abuse experienced by nursing students in clinical practice had significant effects on emotional labor $(\mathrm{F}=25.480, \mathrm{p}<.001)$, which accounted for $10.4 \%$. In particular, verbal abuse from nurses among offenders had significant effects on their emotional labor $(\beta=.330, \mathrm{t}=5.048, \mathrm{p}<.001)$. Disregarding verbally of verbal abuse types had significant effects on their emotional labor $(\beta=.228, \mathrm{t}=4.353, \mathrm{p}<.001)$.

Verbal abuse experienced by the subjects also had significant effects on clinical practice stress $(\mathrm{F}=108.266, \mathrm{p}<.001)$, which accounted for $33.8 \%$. Verbal abuse from nurses had significant effects on clinical practice stress $(\beta=.584, \mathrm{t}=10.405, \mathrm{p}<.001)$. Finishing talk one-sidedly of verbal abuse types had significant effects on clinical practice stress $(\beta=.520, \mathrm{t}=8.805, \mathrm{p}<.001)$. $\langle$ Table 5> 
Table 5. Effect of Verbal Abuse on Emotional Labor and Clinical Practice Stress $(N=212)$

\begin{tabular}{|c|c|c|c|c|c|c|c|c|c|}
\hline $\begin{array}{c}\text { Dependent } \\
\text { variable }\end{array}$ & $\begin{array}{l}\text { Independent } \\
\text { Variables }\end{array}$ & B & SE & $\beta$ & $\mathrm{t}$ & $p$ & $\begin{array}{c}\text { Adjust } \\
\mathrm{R}^{2}\end{array}$ & $\mathrm{~F}$ & $p$ \\
\hline \multirow[b]{2}{*}{ Emotional labor } & Constant & 2.669 & .128 & & 20.9000 & $<.001$ & \multirow[b]{2}{*}{.104} & \multirow[b]{2}{*}{25.480} & \multirow[b]{2}{*}{$<.001$} \\
\hline & $\begin{array}{l}\text { Verbal abuse } \\
\text { from RN }\end{array}$ & .298 & .059 & .330 & 5.048 & $<.001$ & & & \\
\hline \multirow{2}{*}{$\begin{array}{c}\text { Clinical practice } \\
\text { stress }\end{array}$} & Constant & 2.231 & .089 & & 24.954 & $<.001$ & \multirow{2}{*}{.338} & \multirow{2}{*}{108.266} & \multirow{2}{*}{$<.001$} \\
\hline & $\begin{array}{l}\text { Verbal abuse } \\
\text { from RN }\end{array}$ & .430 & .041 & .584 & 10.405 & $<.001$ & & & \\
\hline
\end{tabular}

Table 6. Effect of Verbal Abuse Types of Nurses on Emotional Labor and Clinical Practice Stress ( $N=212)$

\begin{tabular}{|c|c|c|c|c|c|c|c|c|c|}
\hline $\begin{array}{l}\text { Dependent } \\
\text { variable }\end{array}$ & $\begin{array}{l}\text { Independent } \\
\text { Variables }\end{array}$ & $B$ & SE & $\beta$ & $\mathrm{t}$ & $p$ & $\begin{array}{c}\text { Adjust } \\
\mathrm{R}^{2}\end{array}$ & $\mathrm{~F}$ & $p$ \\
\hline \multirow[b]{2}{*}{ Emotional labor } & Constant & 2.931 & .090 & & 32.694 & $<.001$ & \multirow[b]{2}{*}{.107} & \multirow[b]{2}{*}{18.950} & \multirow[b]{2}{*}{$<.001$} \\
\hline & $\begin{array}{l}\text { Disregarding } \\
\text { verbally }\end{array}$ & .151 & .035 & .288 & 4.353 & $<.001$ & & & \\
\hline \multirow{2}{*}{$\begin{array}{c}\text { Clinical practice } \\
\text { stress }\end{array}$} & Constant & 2.616 & .064 & & 41.165 & $<.001$ & \multirow{2}{*}{.267} & \multirow{2}{*}{77.527} & \multirow{2}{*}{$<.001$} \\
\hline & $\begin{array}{l}\text { Finishing talk } \\
\text { one-sidedly }\end{array}$ & .186 & .021 & .520 & 8.805 & $<.001$ & & & \\
\hline
\end{tabular}

\section{Discussion}

This is a descriptive research that investigates verbal abuse, emotional labor, and clinical practice stress nursing students experienced in clinical practice. This research determines the effects of verbal abuse on emotional labor and clinical practice stress. It aims to provide basic data that could help develop a plan to prevent verbal abuse in clinical practice, create a safe practice environment, lower the level of emotional labor in practice, and reduce practice stress.

As most of the nursing students in this study scored 1.52 to 2.13 on average for verbal abuse during nursing practice, they were less likely to experience verbal abuse than the nurses in the previous research [20]. This is probably because nursing students spend less time in nursing patients, take less responsibility than nurses, and rarely make significant nursing interventions among nursing patients. However, the most frequent type of verbal abuse was speaking impolitely and the offenders included nurses and patients and their family. This was probably because nursing students were regarded simply as young students, not as pre-service nurses.

They scored an average of 3.28 out of 5 for the level of emotional labor. This is consistent with the report $[17,26]$ that nursing students also experienced emotional labor. Like nurses, nursing students were found to experience emotional labor at the moderate or higher level, which was lower than that for nurses. Nursing students come to observe nurses' attitudes and behaviors intensively during practice, connect the method of nursing patients they have observed without their own autonomous judgment or will with the knowledge they have acquired in the curriculum, and repeat the expression rules acquired 
from nurses. It is believed that they experience emotional labor in such a process. They may have lower levels of emotional labor than nurses probably because they have interrelationships with patients or with the medical staff as a part of learning and learn to nurse patients through direct or indirect experience. Among the sub-areas of emotional labor, they scored an average of 3.75 for frequency of emotional expression. This result is consistent with Kang [27] who conducted research among nursing students. Such a high frequency of emotional expression was due to the intentional expression of emotions they needed to show in nursing patients during practice.

Meanwhile, the subjects scored an average of 3.12 out of 5 for the level of clinical practice stress. Among its sub-areas, they scored highest with 3.92 for stress from the practical education environment and 3.37 for the burden of practical tasks. This is similar to the result of Kim and Lee [4]. To relieve clinical practice stress for nursing students, it is necessary to make educational and environmental improvement that can reduce the burden of practical tasks. Since limited space and facilities for practice and the practice programs based on ward tasks due to the quantitative expansion of nursing schools have become stressors [28], it is necessary to solve these problems. Full discussion should be made about the division of duties and tasks for students in practice with the objective of reducing stress in the practical education environment.

The verbal abuse students experienced in clinical practice had significantly positive correlation with emotional labor and clinical practice stress and there was strong correlation between emotional labor and clinical practice stress. Nursing students try to control their emotions in the learning course of clinical practice to be employed as a professional and make efforts to adapt their emotions to the expression codes required of pre-service nurses. Such an emotional effort may serve as a stressor, increasing stress in the entire clinical practice.

The verbal abuse students experienced in clinical practice accounted for about $10 \%$ of emotional labor and $33.8 \%$ of clinical practice stress. This result demonstrates that the verbal abuse students experience is a principal practice stressor. Since nursing students' exposure to verbal abuse can negatively affect the formation of a good nursing value, it is necessary to develop methods to prevent verbal abuse and to cope with it within medical institutions.

In summary, it is necessary to prevent such negative experiences as verbal abuse to which students can be exposed in practice sites and give education constantly about how to cope with it with the aim of managing and relieving stress related to clinical practice essential to the nursing curriculum. It is also necessary to make efforts to relieve emotional labor through the programs to reduce conflicts caused by emotional dissonance or emotional efforts. These efforts are expected to make ultimate contributions to the qualitative growth of nursing education.

\section{Conclusion}

To contribute to more efficient nursing education, this study aimed to investigate verbal abuse, emotional labor, and clinical practice stress nursing students might experience during clinical practice.

Verbal abuse has been an issue briefly considered by researchers. Studies related to interpersonal conflict which consider the potential impact of under-reporting have been published from a wide range of healthcare environment including mental health, learning disability. In addition, the effects of emotional labor in health care are being explored globally mental health. Having been involved in clinical nursing practice and nursing education for years, we discovered that nursing students often felt stressed during clinical practice

The subjects experienced moderate or severe clinical practice stress and a great degree of emotional labor in this study. It is believed that verbal abuse from diverse offenders may cause them to suffer higher levels of practice stress and emotional labor. On the basis 
of these results, it is necessary to give attention to the exposure to verbal abuse and emotional labor of nursing students, who are pre-service nurses, and make a plan to develop programs for them to prevent and cope with the situation and create a safe environment for practice. The results of this study have limitations in being generalized since the research is cross-sectional, with convenience sampling made with nursing students in a city.

\section{References}

[1] N. S. Ha and M. S. Choi, "The relationship between leadership styles and self-esteem, satisfaction of clinical practice in nursing students", The Journal of Korean Nursing Administration Academic Society, vol.11, no.1, (2005), pp.1-9.

[2] H. S. Kim, "A Study on Relationship between Stress of Clinical Practice and Clinical Competency in Nursing Students", Journal of Korean Public Health Nursing, vol.16, no.1, (2002), pp.64-67.

[3] M. Y. Park and S. E. Kim, "A study on first clinical practice experience of nursing college students", Journal of Korean Academy Society Nursing Education, vol. 6, no.1, (2000), pp.23-35.

[4] S. L. Kim and J. E. Lee, "Relationship among Stress Coping Strategies, and Self-esteem in Nursing Students Taking Clinical Experience", The Journal of Korean academic society of nursing education, vol.11, no.1, (2005), pp.98-106.

[5] W. Evans and B. Kelly, "Pre-registration diploma student nurse stress and coping measures", Nurse Education Today, vol.24, (2004), pp.219-228.

[6] H. J. Park and I. S. Jang, "Stress, Depression, Coping Styles and Satisfaction of Clinical Practice in Nursing Students", The Journal of Korean academic society of nursing education, vol.16, no.1, (2010), pp.14-23.

[7] E. Lindop, "A complementary therapy approach to the management of individual stress among student nurses", Journal of advanced Nursing, vol.18, no.10, (1993), pp.578-1585.

[8] A. R. Hochschild, "The managed heart", Berkeley: University of California Press, (1983).

[9] P. Smith, "The emotional labor of nursing", London, UK: Macmillan, (1992).

[10] B. Gray, "The emotional labor of nursing defining and managing emotions in nursing work", Nurse Education Today, vol.29, no.2, (2009), pp.168-175.

[11] R. McClure and C. Murphy, "Contesting the dominance of emotional labor in professional nursing", Journal of Health Organization and Management, vol.21, no.2, (2007), pp.101-120.

[12] T. Huynh, M. Alderson and M. Thompson, "Emotional labor underlying caring: an evolutionary concept analysis", Journal of Advanced Nursing, vol.64, no.2, (2008), pp.195-208.

[13] A. Henderson, "Emotional labor and nursing: An under-appreciated aspect of caring work", Nursing Inquiry, vol.8, no.2, (2001), pp.130-138.

[14] P. Smith and B. Gray, "Reassessing the concept of emotional labor in student nurse education: role of link lecturers and mentors in a time of change", Nurse Education Today, vol.21, no.3, (2001), pp.230237.

[15] B. Hunter and P. Smith, "Emotional labor: Just another buzz word?", International Journal of Nursing Studies, vol.44, no.6, (2007), pp.859-861.

[16] B. O. Kang and S. A. Ji, "Experiences and process of patients' healing relation with nurses", Journal of Korean Academy of Nursing Administration, vol.1, no.1, (1995), pp.112-131.

[17] G. Msiska, P. Smith and T. Fawcett, "Exposing emotional labour experienced by nursing students during their clinical learning experience: A Malawian perspective", International Journal of Africa Nursing Sciences, (2014), pp.43-50.

[18] J. A. Morris and D. C. Feldman, "The Dimensions, antecedents and consequences of emotional labor", Academy of Management Review, vol.21, no.4, (1996), pp.986-1010.

[19] A. Grandey, "Emotion regulation in the workplace: A new way to conceptualize emotional labor", Journal of Occupational Health Psychology, vol.5, (2000), pp.95-110.

[20] H. J. Kwon, H. S. Kim, K. S. Choi and K. S. Lee, "A Study on Verbal Abuse Experienced at Medical Centers", Journal of Korean Clinical Nursing Research, vol.13. no.2, (2007), pp.113-124.

[21] H. Y. Woo, "A study on verbal abuse, emotional labor and clinical practice stress of nursing students", Advanced Science and Technology Letters, vol.88, (2015), pp.83-86.

[22] J. S. Yoon, "A study of violence experience from patients and their families and job satisfaction of emergency department nurses", Unpublished master's thesis, The Ulsan University, (2004).

[23] M. Y. Shin, "Violence, burnout and turnover intention of the nurses in a general hospital", Unpublished master's thesis, The Hanyang University, (2011).

[24] M. J. Kim, "Effects of the Hotel Employee's Emotional Labor upon the Job", Journal of Hospitality and Tourism Studies, vol.21, no.2, (1998), pp.129-141.

[25] D. L. Beck and R. Srivastsva, "Perceived level and sources of stress in baccalaureate nursing students", Journal of Nursing Education, vol.30, no.3, (1991), pp.127-133.

[26] K. Jack and C. Wibberley, "The meaning of emotion work to student nurses: A Heideggerian analysis", International Journal of Nursing Studies, vol.5, (2014), pp.900-907. 
[27] S. Y. Kang, "Impact of Nursing Students' Emotional Labor on Burnout during Nursing Practice in a Hospital: Moderating Effect of Emotional Intelligence", Journal of Korean academic nursing administration, vol.21, no.1, (2015), pp.77-87.

[28] N. Y. Yang and S. Y. Moon, "Relationship of Self-leadership, Stress and Satisfaction in Clinical Practice of Nursing Students", The Journal of Korean Nursing Administration Academic Society, vol.17, no.2, (2011), pp.216-225.

\section{Author}

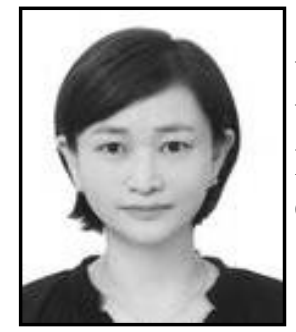

Hae Young Woo is a lecturer at college of nursing, Hanyang University. She received her Ph.D. degree from Hanyang University, Korea in 2005. Currently, she is a researcher at HEALING LAB. Her research interests include nursing education, healing environment, elderly and family. 